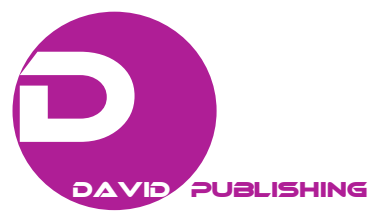

\title{
Histological Study of the Therapy in the Essential Oil of Laurusnobilis L. from the West Algerian in Rats Wistar Infected
}

\author{
Ould Yerou Karima ${ }^{1}$, Meddah Boumedienne ${ }^{1}$, Tir Touil ${ }^{1}$ and Tou Abdenacer ${ }^{2}$ \\ 1. Laboratory of Bioconversion, Microbiological Engineering and Safety, University of Mascara, Mascara 29000, Algeria \\ 2. Laboratory Search "Cancer and the Environment”, Department of Medcine, University of Sidi Bel Abbes, SISI BEABBES 22000, \\ Algeria
}

\begin{abstract}
Laurusnobilis L. is an aromatic plant, widespread in Algeria and widely used by local people as a source of spice for its medicinal properties. The essential oil of this plant native to western Algeria is the subject of the study. The extraction of the essential oil was carried by steam distillation, the yield obtained from the leaves (1.5\%), Wister rats male weight between $100 \mathrm{~g}$ and $80 \mathrm{~g}$ were infected with Salmonella then treated with anessential oil of Laurusnobilis L.. After sacrifice of the rats, histological examination of the intestines and internal organ (liver and spleen) shows the therapy of this magic plant- "Laurusnobilis L.".
\end{abstract}

Key words: Laurusnobilis L., steam distillation, essential oil, histology, Wistar rats.

\section{Introduction}

Laurusnobilis L.- -native to Mediterranean regions is also known as sweet bay, bay laurel, Grecian laurel, true bay and bay [1]. The dried leaves are used extensively in cooking, and the essential oil is generally used in the flavourings industry [2]. Laurel essential oil, called laurel leaf oil or sweet bay essential oil is used for the preparation of hair lotion due to its antidandruff activity and for the external treatment of psoriasis [3].

\section{Materials and Methods}

\subsection{Materials}

Plant materials: The leaves of Laurusnobilis L. were harvested in April and June 2014 from Mascara (Algeria), this leaves were dried for 10-15 days in darkness at room temperature.

Isolation of the essential oils: Essential oil of leaves of Laurusnobilis L. is obtained by steam distillation of

Corresponding author: Ould Yerou Karima, Ph.D., main research field: biology. water for $2 \mathrm{~h}$ and $30 \mathrm{~min}$ [4].

Bacterial strains: Salmonella sp. was from collected waste water, identified at the Bioconversion Laboratory, Microbiological Engineering and Safety, University of Mustapha Stambouli-Mascara (Algeria).

Animals: Specic Pathogen-Free (SPF) male Wistar-Unilever (WU) rats were obtained from the farm of university of Mascara (Algeria). The animals $-5 \pm 8$ weeks of age were housed individually in macrolon cages, $1 \pm 2$ weeks prior to inoculation. Drinking water and conventional diet were provided adlibitum. The breeding colony of the animals was prescreened/monitored for endogenous pathogenic viruses and bacteria, which was negative.

\subsection{Methods}

The essential oil dose that Laurusnobilis L. selected is $1 \mathrm{~g} / \mathrm{kg}$ (each rat receiving by gavage $1 \mathrm{~mL}$ of a solution: essential oil diluted in physiological saline). The study involves 21 rats after a period of habituation. Rats were weighed and identified by marking on the tail. The animals were divided into 
three groups of seven animals each, one of which is the control group, and the rats were left without power for 24 hours before testing.

Group 1: received $1 \mathrm{~mL}$ of bacterial suspension and then $1 \mathrm{~mL}$ of the aqueous solution the first day, and after six days, only received $1 \mathrm{~mL}$ of the aqueous solution;

Group 2: received $1 \mathrm{~mL}$ of the aqueous solution for seven days;

Group 3: received tap water as witness.

\subsection{Animal Sacrifice}

The rats were weighed and then anaesthetized just before they were sacrificed. The abdominal cavity was opened up through a midline abdominal incision to expose the small intestine, liver and spleen.

\subsection{Histological Analysis}

As described by Mediouni-Ben Jemâa, J. [5], the organs were cut in slabs of about $0.5 \mathrm{~cm}$ thick and fixed in Bouin's fluid for one day after which it was transferred to $70 \%$ alcohol for dehydration. The tissues were passed through $90 \%$ alcohol and chloroform for different durations before they were transferred into two changes of molten paraffin wax for $20 \mathrm{~min}$ each in an oven at $57{ }^{\circ} \mathrm{C}$. Serial sections of $5 \mu \mathrm{m}$ thick were obtained from a solid block of tissue and were stained with haematoxylin and eosin stains, after which they were passed through a mixture of equal concentration of xylene and alcohol. Following clearance in xylene, the tissues were oven-dried. Light microscopy was used for the evaluations.

\section{Results and Discussion}

Fig. 1 shows the small intestine of rat infected with Salmonella sp.-destruction of crypts and diffuse epithelial attening and erosion, massive mixed infiltration in (sub) mucosa.

Fig. 2 shows the small intestine of rat treated with essential oils of Laurusnobilis L..

Fig. 3 shows the liver of rat infected with Salmonella sp.-inflammation, necrosis of hepatoc replaced by macrophages and steatosis (fat vacuole charge).

Fig. 4 shows the liverof rat treated with essential oils of Laurusnobilis L. - a total disappearance of macrophages in hepatocytes.

Fig. 5 shows the spleen of rat infected with Salmonella sp.-inflammatory histiocytose reaction, presence in the red pulp of histiocytes with eosinophilic cytoplasm containing rounded debris of erythrocytes and polymorphonuclear phagocytosis (possibility of suppurative abscesses or foci), and reduced white pulp.

Fig. 6 shows the spleen of rat treated with essential oils of Laurusnobilis L. has no histiocytes in the red pulp.

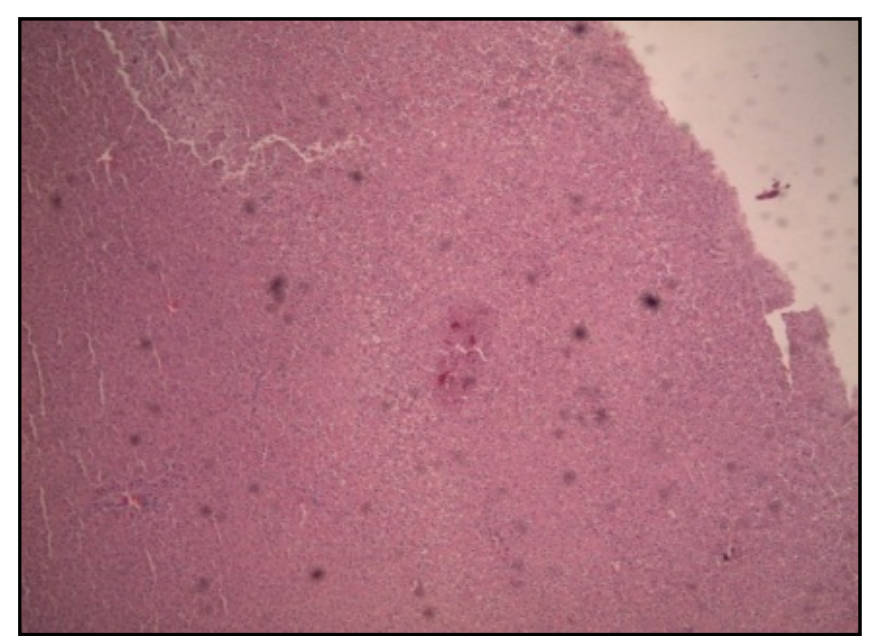

Fig. 1 Small intestine of rat infected (Haematoxylin and eosin stains, $\times 400$ ). 
Histological Study of the Therapy in the Essential Oil of Laurusnobilis L. from the West Algerian in Rats Wistar Infected

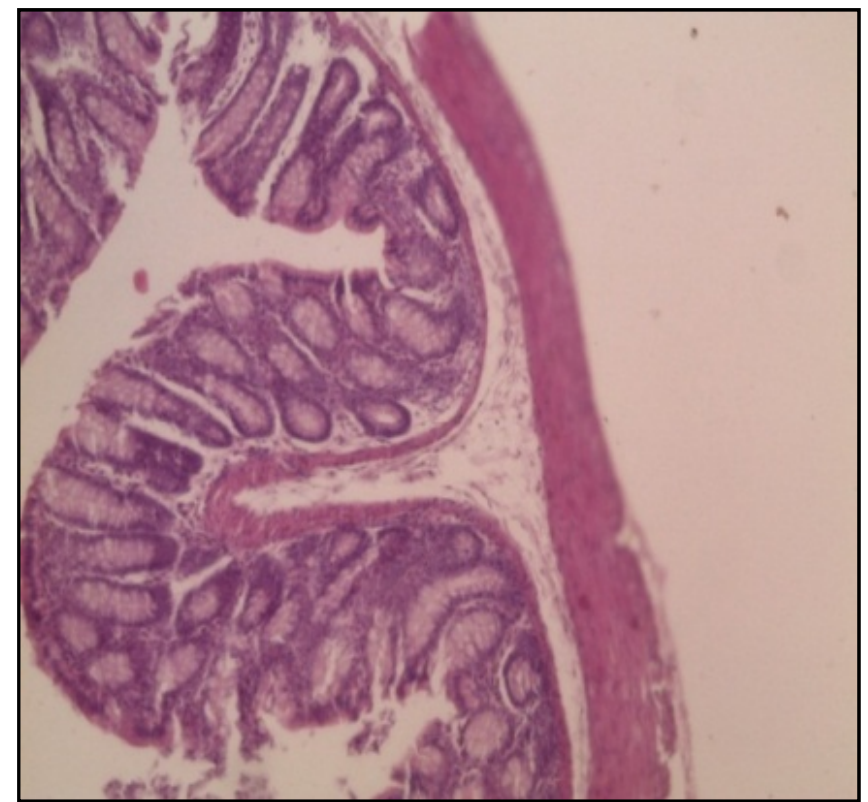

Fig. 2 Small intestine of rat treated (Haematoxylin and eosin stains, $\times 400$ ).

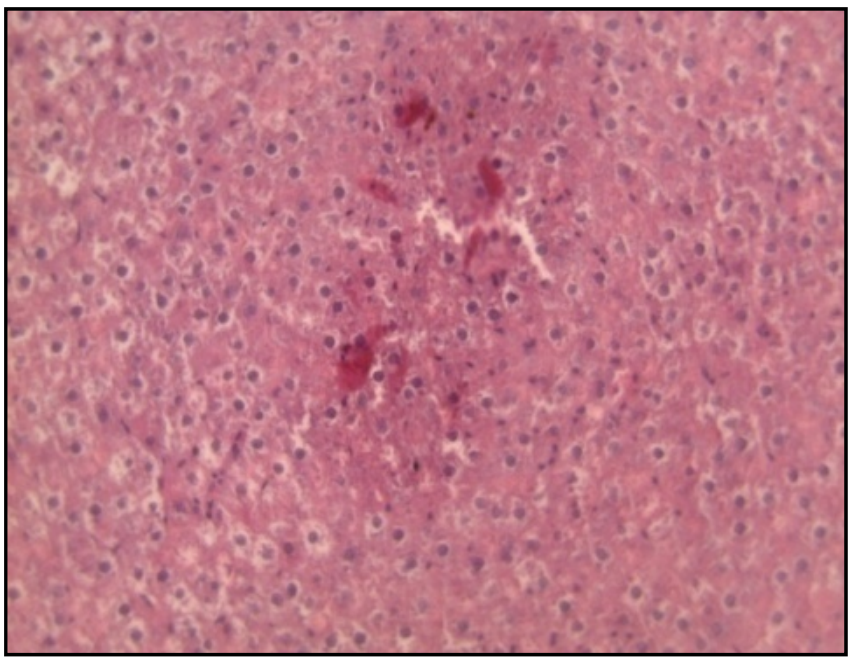

Fig. 3 Liver of rat infected (Haematoxylin and eosin stains, $\times 400$ ).

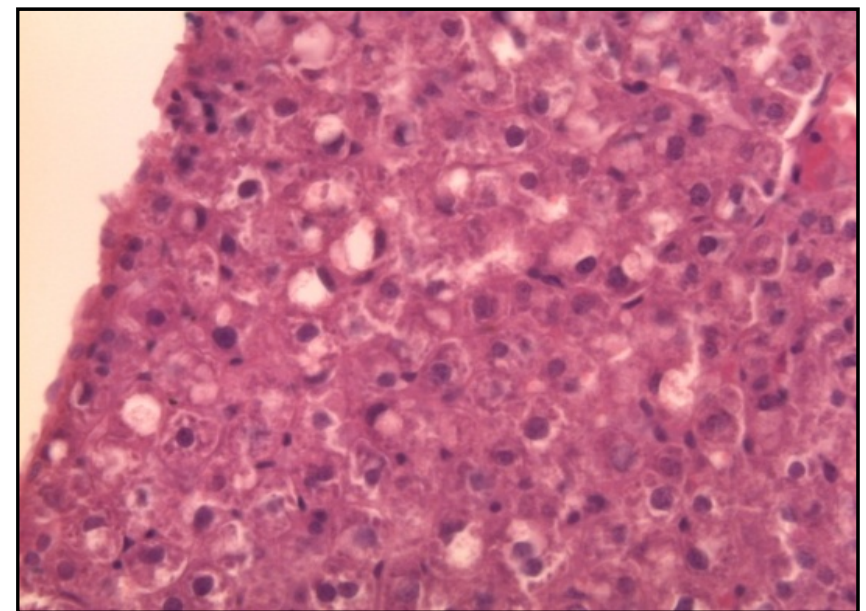

Fig. 4 Liver of rat treated (Haematoxylin and eosin stains, $\times 400$ ). 


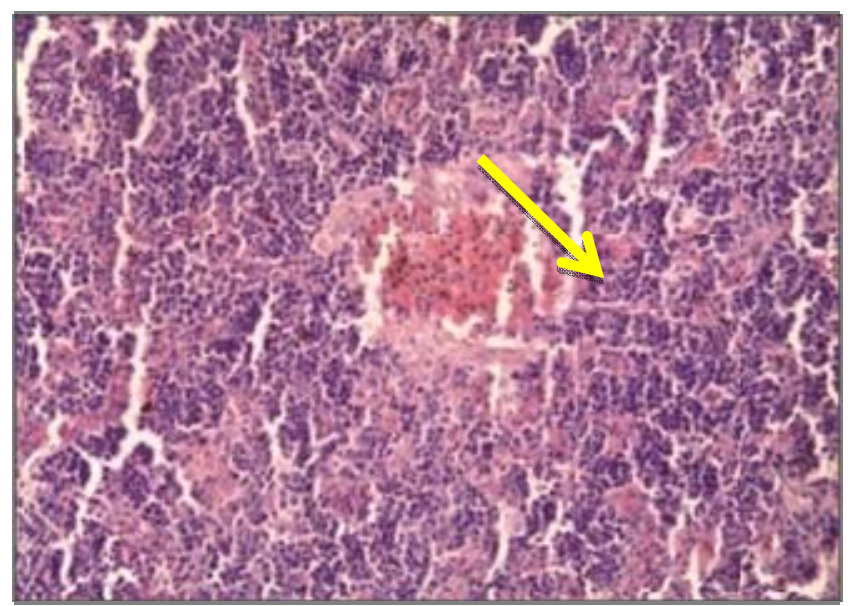

Fig. 5 Spleen of rat infected (Haematoxylin and eosin stains, $\times$ 400).

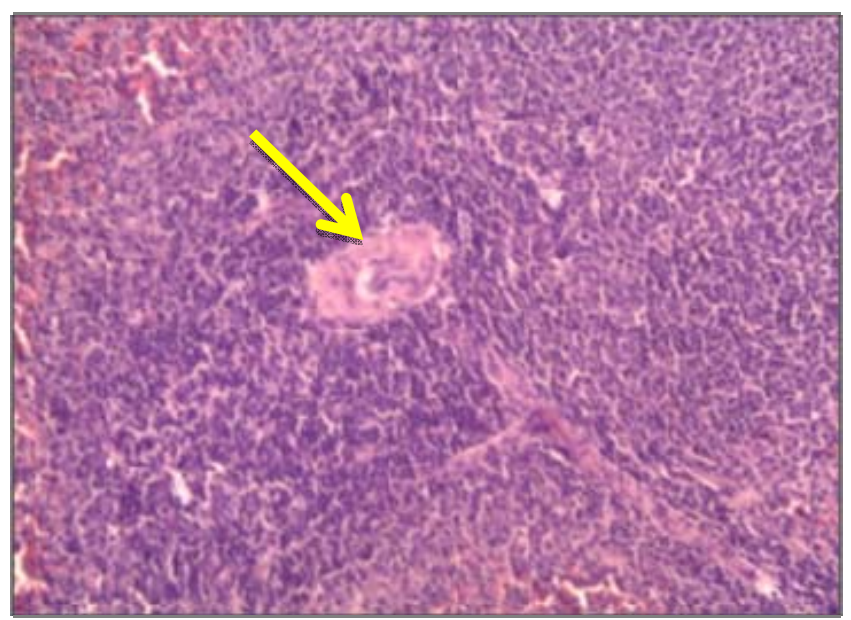

Fig. 6 Spleen of rat treated (Haematoxylin and eosin stains, $\times 400$ ).

After histological analysis, the results showed that the essential oil of Laurusnobilis L. was effective against Salmonella sp.. The toxicity of this essential oil could be attributed to its compounds, the main trepan found was 1,8-cineole [6].

\section{References}

[1] Chaouche, T., Hadouchi, F., Lazouni, H. A., Dahmani, A., Amel, S., and Benmansour, A. 2011. "Physicochemical Study Essential Oils of Laurusnobilis L. according to Its Conservation." Der Pharma Chemical 3 (2): 411-417.

[2] Davis, J. 1994. "Inactivation of Antibiotics and the Dissemination of Resistance Genes Science." Genes Science 264: 375-382.

[3] Saalu, L. C., Osinubi, A, A., Akinbami, A. A., Yama, O.
E., Oyewopo, A. O., and Enaibe, B. U. et al. 2011. Leaf "Extract Modulates the Evidences of Hydroxyurea-Induced Testicular Derangement." Int. Jof. Applied Research in Natural Prod. 2: 32-45.

[4] Demir, V., Guhan, T., Yagcioglu, A. K. and Ddegir Encioglu, A. 2004. "Mathematical Modeling and the Determination of Some Quality Parameters of Air-dried Bay Leaves.” Biosystems Engineering 88 (3): 325-355.

[5] Mediouni-Ben Jemâa, J., Tersim, N., Boushih, E., Taleb-Toudert, K., and Khouja, M. L. 2013. "Fumigant Control of the Mediterranean Flour Moth Ephestia kuehniella with the Noble Laurel Laurusnobilis L. Essential Oils." Tunisian Journal of Plant Protection 8: $33-44$.

[6] Barla A., Topçu, G., Oksuz, S., Tumen, G., and Kingston, D. G. I. 2007. "Identifcation of Cytotoxic Sesquiterpenes from Laurusnobilis L..” Food Chemistry 104: 1484-1487. 